\title{
Solubility Enhancement of Raloxifene Using Inclusion Complexes and Cogrinding Method
}

\author{
Payal H. Patil, Veena S. Belgamwar, Pratibha R. Patil, and Sanjay J. Surana \\ Department of Pharmaceutics, R. C. Patel Institute of Pharmaceutical Education and Research, Near Karvand Naka, \\ Shirpur, Dhule, Maharashtra 425405, India \\ Correspondence should be addressed to Payal H. Patil; pharmapayal@gmail.com
}

Received 16 October 2012; Accepted 12 December 2012

Academic Editor: Antonio Ruiz Medina

Copyright (C) 2013 Payal H. Patil et al. This is an open access article distributed under the Creative Commons Attribution License, which permits unrestricted use, distribution, and reproduction in any medium, provided the original work is properly cited.

\begin{abstract}
The objective of the present work was to enhance the solubility and dissolution of practically water-insoluble drug raloxifene $\mathrm{HCl}$ (RLX), for the same two approaches that were used. In the first approach, drug was kneaded with hydroxypropyl- $\beta$-cyclodextrin $(\mathrm{HP} \beta \mathrm{CD})$, and in the second one drug was cogrinded with modified guar gum (MGG). The drug-cyclodextrin complex and drug-MGG cogrind mixtures were characterized by differential scanning calorimetry, X-ray diffraction studies, scanning electron microscopy, and Fourier transform infrared spectroscopy. The solubility and dissolution study reveals that solubility and dissolution rate of RLX remarkably increased in both methods. It was concluded that the prepared inclusion complex showed a remarkable increase in solubility and dissolution of poorly water-soluble drug raloxifene. In the cogrinding mixture, a natural modified gum is used as a surfactant and enhances the solubility and dissolution of RLX without requiring addition of organic solvent or high temperature for its preparation; thus, process is less cumbersome and cost effective. But when both methods were compared; $\mathrm{HP} \beta \mathrm{CD}$ complexation method showed significant enhancement of drug solubility.
\end{abstract}

\section{Introduction}

Solubility of a drug is an important property that mainly influences the extent of oral bioavailability. Enhancement of oral bioavailability of poorly water soluble drugs is the most challenging aspect of drug development [1]. Most of the new chemical entities suffer from low bioavailability due to their low aqueous solubility and dissolution. Therefore, it is very important to find appropriate formulation approaches to improve aqueous solubility and bioavailability of poorly aqueous soluble drugs [2].

Raloxifene (marketed as Evista by Eli Lilly and Company) is an oral second generation selective estrogen receptor modulator (SERM) used to prevent osteoporosis in postmenopausal women. It is 2-(4-hydroxyphenyl)-3-(\{4-[2(piperidin-1-yl) ethoxy] phenyl\} carbonyl)-1-benzothiophen-6-ol that has estrogenic actions on bone and antiestrogenic actions on the uterus and breast. It belongs to class II drug according to biopharmaceutical classification system (BCS), that is, low solubility and high permeability. But raloxifene has very less bioavailability, only $2 \%$, and it would be advantageous to increase the solubility of such molecule. Raloxifene is available in salt form as raloxifene $\mathrm{HCl}$ [3]. The drug is poorly absorbed from the gastrointestinal (GI) tract therefore; it is important to enhance aqueous solubility and dissolution rate which may lead to enhancement of bioavailability from its oral solid dosage forms.

In this study, two strategies were used, which were aimed at improving the aqueous solubility. The first one is complexation of drugs with cyclodextrin, and the second one is Cogrinding with natural polymers. Cyclodextrins (CDs) are cyclic macromolecules, obtained by the degradation of starch by $\alpha$-1,4-glucan-glycosyl transferase. They have also been used to improve drug stability, bioavailability, or toxicity profiles. Moreover, chemically modified cyclodextrins have been extensively used. Among the chemically modified cyclodextrins, 2-hydroxypropyl- $\beta$-cyclodextrin (HP- $\beta$-CD) deserves special attention due to its favorable physicochemical and biological properties [4]. Kneading method was employed for the preparation of raloxifene $\mathrm{HCl}$ with $\mathrm{HP} \beta \mathrm{CD}$, and the effect of complexation on the solubility and dissolution rate of 
raloxifene was evaluated. In the second approach, Cogrinding of raloxifene $\mathrm{HCl}$ with modified guar gum was done. Guar gum (GG) is a gum obtained from the ground endosperms of Cyamopsis tetragonolobus (Leguminosae family). It is composed of galactan and mannan units combined through glycosidic linkages [5]. The natural polymers have surfactant activity [6] that enhances the solubility and dissolution rate of drug, but high viscosity of these polymers is a limitation for them to be used as carriers for dissolution enhancement [7]; this problem is overcome by heating of the polymers at particular time and temperature condition which reduces the viscosity [6].

The present study was carried out to investigate the inclusion complex of raloxifene $\mathrm{HCl}$ and $\mathrm{HP} \beta \mathrm{CD}$ in the solid state and the RLX-MGG Cogrind mixture using Xray diffractometry (XRD) differential scanning calorimetry (DSC), Fourier transform infrared spectroscopy (FTIR), and scanning electron microscopy (SEM). The objective of this study was to enhance solubility and dissolution rate of RLX which may lead to enhancement of bioavailability of this drug $[1,8,9]$.

\section{Materials and Methods}

2.1. Materials. Raloxifene (RLX) was obtained as a gift sample from Zydus Cadila Healthcare Ltd., Ahmedabad, India. $\mathrm{HP} \beta \mathrm{CD}$ was gifted by Roquette Pharma, France and, Guar gum (GG) was gifted by Lucid Colloids Ltd., Sewari, Mumbai. Methanol and all other reagents used were of analytical grade.

\subsection{Methods}

\subsubsection{Kneading Method [8, 10]}

Development of Inclusion Complex of Raloxifene with $H P \beta C D$. As raloxifene $\mathrm{HCl}$ is practically insoluble in water, an inclusion complex of the antiosteoporotic raloxifene $\mathrm{HCl}$ (RLX) in hydroxypropyl- $\beta$-cyclodextrin (HP $\beta \mathrm{CD}$ ) was prepared and characterized.

Preparation of RLX-HP $\beta C D$ Inclusion Complex. It was prepared by Kneading method. The mixture of RLX and HP $\beta C D$ in 1:1 molar ratio was triturated in a mortar with a small volume of water-methanol $(1: 2 \mathrm{v} / \mathrm{v})$ solution. The thick slurry formed was kneaded for $45 \mathrm{~min}$ and then dried at $45^{\circ} \mathrm{C}$. The dried mass was pulverized and sieved through sieve no. 60.

\subsubsection{Cogrinding Method}

Modification of Polymers [1]. Guar Gum was modified by heating method. Powdered gum was taken in a porcelain bowl and kept in hot air oven at different temperatures and different time intervals. The viscosity and swelling index were studied, which reveals that viscosity decreases as the time and temperature of heating increases but swelling index remains unaffected. It was observed that guar gum produced colour change on heating above $130^{\circ} \mathrm{C}$ and $120^{\circ} \mathrm{C}$ more than $2 \mathrm{hrs}$ respectively. Thus, $120^{\circ} \mathrm{C}$ and $2 \mathrm{hrs}$ conditions were selected for modification of polymers. Finally, modified gum was sieved through mesh no. 100 and stored in airtight container.

\section{Characterization of Polymers}

Swelling Index (SI) $[1,9,11]$. About $1 \mathrm{gm}$ of GG and MGG were accurately weighed and transferred to $100 \mathrm{~mL}$ measuring cylinder. The initial volume of powder in measuring cylinder was noted which is denoted as $X_{0}$. Distilled water was added in measuring cylinder up to $100 \mathrm{~mL}$ mark, shaken gently, and cylinder was kept aside for $24 \mathrm{hrs}$. The final volume occupied by polymers was noted after $24 \mathrm{hrs}$, which is denoted as $X_{t}$. Swelling index was calculated according to the following equation:

$$
\mathrm{SI}=\frac{X_{t}-X_{0}}{X_{0}} \times 100 .
$$

Viscosity Measurement [9]. Viscosity of GG and MGG gums was determined by using Brookfield DV-E viscometer (Brookfield engineering laboratory) at $37^{\circ} \mathrm{C}$ and $50 \mathrm{rpm} .1 \%$ $(\mathrm{w} / \mathrm{v})$ solution was prepared in distilled water and used for measuring the viscosity.

Preparation of Cogrind Mixture [1]. Cogrind mixtures of drug and modified gum were prepared in different ratio such as $1: 1$ to $1: 9$. The ratio was optimized by using solubility data. The sample of drug and gum in $1: 1 \mathrm{w} / \mathrm{w}$ ratio was Cogrinded for $25 \mathrm{~min}$, in ceramic mortar and sieved through mesh no. 100 . The same method was applied for all ratios of drug with polymer. The Cogrind mixture of RLX with MGG and GG denoted as RLX-MGG and RLX-GG, respectively.

Ratio Optimization (Drug: Polymer). Samples were placed in $10 \mathrm{~mL}$ solvent ( $\mathrm{pH} 7$ phosphate buffer) in teflon facing screw capped vial and kept at equilibrium for a period of $24 \mathrm{hrs}$ on orbital shaking incubator (Remi Instruments Ltd.) at $37 \pm 0.5^{\circ} \mathrm{C}$ and $50 \mathrm{rpm}$. The contents of vials were filtered through 0.2 micron filter and analyzed by UV-Visible spectrophotometer (UV 1601, Shimadzu) at $287 \mathrm{~nm}$. As shown in Table 3, the solubility increases as the gum concentration increases, the optimized ratio was found to be $1: 8 \mathrm{w} / \mathrm{w}$ as further increase in ratio to $1: 9 \mathrm{w} / \mathrm{w}$ showed no significant increase in solubility of drug. Cogrinding mixtures of RLX with MGG and GG were prepared in 1:8 w/w ratio.

\subsubsection{Characterization of $H P \beta C D$ Inclusion Complex and Cogrind Mixture [1, 9]}

(1) Differential Scanning Calorimetry (DSC). DSC studies of raloxifene $\mathrm{HCl}, \mathrm{HP} \beta \mathrm{CD}, \mathrm{MGG}$, RLX-HP $\beta \mathrm{CD}$ inclusion complex, and RLX-MGG Cogrind mixture were performed using differential scanning calorimeter (Mettler Toledo DSC 1 Star System, Zurich, Switzerland) at heating rate of $10^{\circ} \mathrm{C} / \mathrm{min}$ from 40 to $340^{\circ} \mathrm{C}$ in nitrogen atmosphere. 
(2) X-Ray Diffractometry (XRD). Powder XRD patterns of raloxifene $\mathrm{HCl}, \mathrm{HP} \beta \mathrm{CD}, \mathrm{MGG}$, RLX-HP $\beta \mathrm{CD}$ inclusion complex, and RLX-MGG Cogrind mixture were recorded using diffractogram (Bruker AXS, D8 Advance, Germany) and $\mathrm{Cu}-\mathrm{K} \alpha$ radiation. Diffractogram was run at a scanning speed of $2^{\circ} / \mathrm{min}$ and a chart speed of $2^{\circ} / 2 \mathrm{~cm}$ per $2 \theta$.

(3) Fourier Transform Infrared Spectroscopy (FT-IR). Raloxifene $\mathrm{HCl}, \mathrm{HP} \beta \mathrm{CD}, \mathrm{MGG}$, RLX-HP $\beta \mathrm{CD}$ inclusion complex, and RLX-MGG Cogrind mixture were mixed separately with IR grade $\mathrm{KBr}$ in the ratio of $1: 100$, and corresponding pellets were prepared by applying 10 metric ton of pressure in hydraulic press. The pellets were then scanned over a wave range of $4000-400 \mathrm{~cm}^{-1}$ in FTIR instrument $(8400 \mathrm{~S}$ Shimadzu).

(4) Scanning Electron Microscopy (SEM). The SEM photographs of raloxifene $\mathrm{HCl}$, RLX-HP $\beta \mathrm{CD}$ inclusion complex, and RLX-MGG Cogrind mixture were obtained by scanning electron microscope (JSM 6390LV, JEOL Model, Japan) with $10 \mathrm{kV}$ accelerating voltage.

Phase Solubility Studies of Inclusion Complex [10, 12]. The phase solubility technique permits the evaluation of the affinity between $\mathrm{HP} \beta \mathrm{CD}$ and raloxifene in water. Phase solubility studies were performed according to the method reported by Higuchi and Connors [13]. As given in Table 1 , raloxifene was taken into vials in an excess amount, and $20 \mathrm{~mL}$ of distilled water was added, containing various concentration of $\mathrm{HP} \beta C D(10-40 \mathrm{mmol})$. These vials were sealed and shaken at $20^{\circ} \mathrm{C}$ for 4 days. This period was considered sufficient to reach equilibrium. Subsequently, the aliquots were withdrawn, using a syringe, and samples were filtered through 0.2 micron filter and appropriately diluted. A portion of the sample was analyzed by UV spectrophotometer (UV 1601, Shimadzu) at $287 \mathrm{~nm}$ against blank prepared in the same concentration of $\mathrm{HP} \beta \mathrm{CD}$ in water so as to cancel any absorbance that may be exhibited by the HP $\beta C D$. The solubility experiments were conducted in triplicate. The apparent stability constant $\left(K_{c}\right)$ of complexes was calculated from the phase solubility diagram using the following equation:

$$
K_{c}=\frac{\text { Slope }}{S_{0}(1-\text { slope })} .
$$

The slope obtained from the initial straight line portion of the plot of raloxifene concentration against $\mathrm{HP} \beta \mathrm{CD}$ concentration, and $S_{0}$ is the equilibrium solubility of raloxifene in water.

Solubility Study of Cogrind Mixture [1,9]. The solubility of RLX, RLX-GG and RLX-MGG were determined in distilled water, $1.2 \mathrm{pH} \mathrm{HCl}$ buffer, and $7.0 \mathrm{pH}$ buffer. The solubility of drug and Cogrinding mixtures were determined by taking an excess amount $30 \mathrm{mg}$ of drug and the Cogrind mixture equivalent to $30 \mathrm{mg}$ of drug, was added in $10 \mathrm{~mL}$ of the previous solvents, in teflon facing screw capped vials. The
TABLE 1: Phase solubility study of raloxifene $\mathrm{HCl}$ in distilled water.

\begin{tabular}{lccccc}
\hline Sr. no. & Formulation code & A1 & A2 & A3 & A4 \\
\hline 1 & Drug $(\mathrm{mg})$ & 20 & 20 & 20 & 20 \\
2 & HP $\beta$ CD $(\mathrm{mg})$ & 20 & 40 & 60 & 80 \\
3 & Distilled Water $(\mathrm{mL})$ & 20 & 20 & 20 & 20 \\
\hline
\end{tabular}

TABLE 2: Characterization of guar gum and modified guar gum. All values are mean \pm S.D, $n=3$.

\begin{tabular}{lcc}
\hline Polymer & Viscosity $(\mathrm{cP})$ & Swelling index $(\%)$ \\
\hline Guar gum & $323 \pm 18.52$ & $2905.46 \pm 6.01$ \\
Modified guar gum & $197 \pm 10.43$ & $2700.69 \pm 10.13$ \\
\hline
\end{tabular}

TABLE 3: Optimization ratio of RLX with guar gum and modified guar gum. All values are mean \pm S.D, $n=3$.

\begin{tabular}{lcc}
\hline \multirow{2}{*}{ Ratio } & \multicolumn{2}{c}{ Concentration $(\mathrm{mg} / \mathrm{mL})$} \\
& RLX-GG & RLX-MGG \\
\hline $1: 1$ & $1.11 \pm 0.041^{*}$ & $0.87 \pm 0.065^{*}$ \\
$1: 2$ & $1.33 \pm 0.005^{*}$ & $1.09 \pm 0.004^{*}$ \\
$1: 3$ & $1.40 \pm 0.109^{*}$ & $1.11 \pm 0.010^{*}$ \\
$1: 4$ & $1.46 \pm 0.017^{*}$ & $2.13 \pm 0.011^{*}$ \\
$1: 5$ & $1.63 \pm 0.012^{*}$ & $2.30 \pm 0.031^{*}$ \\
$1: 6$ & $2.01 \pm 0.015^{*}$ & $2.41 \pm 0.013^{*}$ \\
$1: 7$ & $2.18 \pm 0.056^{*}$ & $3.54 \pm 0.011^{*}$ \\
$1: 8$ & $2.32 \pm 0.015^{*}$ & $3.69 \pm 0.012^{*}$ \\
$1: 9$ & $2.35 \pm 0.007$ & $3.67 \pm 0.023$ \\
\hline
\end{tabular}

${ }^{*}$ Significant $(P$ value $<0.05)$.

TABLE 4: Solubility of RLX and cogrind mixtures in different solvent at $37 \pm 0.5^{\circ} \mathrm{C}$ after $48 \mathrm{hrs}$. All values are mean \pm S.D, $n=3$.

\begin{tabular}{lccc}
\hline Sample & $\begin{array}{c}\text { Medium } \\
(\mathrm{mg} / \mathrm{mL})\end{array}$ & $\begin{array}{c}\text { pH } 1.2 \mathrm{HCl} \\
\text { buffer } \\
(\mathrm{mg} / \mathrm{mL})\end{array}$ & $\begin{array}{c}\mathrm{pH} 7 \text { phosphate } \\
\text { buffer } \\
(\mathrm{mg} / \mathrm{mL})\end{array}$ \\
\hline RLX & $0.097 \pm 0.105$ & $0.082 \pm 0.079$ & $0.076 \pm 0.023$ \\
RLX-GG & $2.090 \pm 0.002^{*}$ & $2.037 \pm 0.160^{*}$ & $2.610 \pm 0.020^{*}$ \\
RLX-MGG & $3.570 \pm 0.27^{*}$ & $3.173 \pm 0.030^{*}$ & $3.870 \pm 0.360^{*}$ \\
\hline
\end{tabular}

${ }^{*}$ Significant $(P$ value $<0.05)$.

samples were kept at equilibrium for a period of $48 \mathrm{hrs}$ on orbital shaking incubator at $37 \pm 0.5^{\circ} \mathrm{C}$ and $50 \mathrm{rpm}$. The contents of vials were filtered through 0.2 micron filter and analyzed by UV-Visible spectrophotometer (UV 1601, Shimadzu) at $287 \mathrm{~nm}$.

2.2.4. In Vitro Dissolution Rate Study [9]. Dissolution rates from RLX, RLX-HP $\beta C D$ inclusion complex, and RLX-MGG Cogrind mixture were determined in $900 \mathrm{~mL}$ of $\mathrm{pH} 6.8$ phosphate buffer at $37 \pm 0.5^{\circ} \mathrm{C}$ with a stirrer rotation speed of $75 \mathrm{rpm}$ using the USP dissolution test apparatus type II (paddle type) (TDT 08L-ELECTROLAB, Mumbai, India). RLX-HP $\beta$ CD inclusion complex and RLX-MGG Cogrind mixture were taken equivalent to $100 \mathrm{mg}$ of RLX. An aliquot of $5 \mathrm{~mL}$ of sample was withdrawn at $5,10,15,30,45$, 
TABLE 5: Dissolution efficiency of RLX, RLX-HP $\beta$ CD inclusion complex, and RLX-MGG cogrind mixture. All values are mean \pm S.D, $n=3$.

\begin{tabular}{lcc}
\hline \multirow{2}{*}{ Sample } & \multicolumn{2}{c}{ Dissolution efficiency } \\
& $\mathrm{DE}_{60}$ & $\mathrm{DE}_{120}$ \\
\hline $\begin{array}{l}\text { Raloxifene } \\
\text { RLX-HP } \beta \text { CD inclusion } \\
\text { complex }\end{array}$ & $83.34 \pm 1.14^{*}$ & $84.41 \pm \pm 2.04$ \\
$\begin{array}{l}\text { RLX-MGG cogrind } \\
\text { mixture }\end{array}$ & $49.70 \pm 1.18^{*}$ & $51.30 \pm 1.54^{*}$ \\
\hline
\end{tabular}

${ }^{*}$ Significant $(P$ value $<0.05)$.

$60,90,105$, and $120 \mathrm{~min}$ with a pipette. The samples were filtered through 0.2 micron filter, suitably diluted and assayed spectrophotometrically at $287 \mathrm{~nm}$. Each dissolution rate test was repeated three times. As a model independent approach, dissolution efficiency (DE) was employed to evaluate the dissolution rate of RLX. DE is defined as the area under the dissolution curve up to the time $t$, expressed as a percentage of the area of the rectangle described by $100 \%$ dissolution in the same time. $\mathrm{DE}_{60}$ and $\mathrm{DE}_{120}$ were calculated from the dissolution data and used for comparison.

2.2.5. Statistical Evaluation. All results are expressed as mean \pm S.D. Differences between the two related parameters were considered statistically significant for $P$ values for less than 0.05. Drug to polymer optimization ratio, solubility determination, and dissolution efficiency results were analyzed by applying one way ANOVA test.

\section{Results and Discussion}

3.1. Development of Inclusion Complex of Raloxifene and $H P \beta C D$. Cyclodextrin (CD) has a hydrophobic central cavity and hydrophilic outer surface and can encapsulate model substrates to form host-guest complexes or supramolecular species. This usually enhances drug solubility in aqueous solution and affects the chemical characteristics of the encapsulated drug. $\mathrm{HP} \beta \mathrm{CD}$ is a hydroxyalkylated- $\beta$-cyclodextrin derivative that combines relatively high water solubility with low toxicity and satisfactory inclusion ability. The binding behavior of hydroxypropyl- $\beta$-cyclodextrin with RLX and the solubilization effect of HP $\beta$ CD toward RLX may provide a useful approach to produce a novel RLX formulation with improved bioavailability.

3.2. Development of Cogrind Mixture of Raloxifene and Modified Guar Gum. The natural polymers are mainly evaluated in industry for their new applications. Due to the less toxic effect and low production cost, these polymers mainly used as drug carrier in pharmaceutical industry. Guar gum has surfactant activity [6], which reduces the contact angle and increases wetting of drug particles, thus enhances solubilization and dissolution of drug particles. This gum has limitation as dissolution enhancing carrier due to their high viscosity. These polymers produce gel layer on the hydrated surfaces which prevents the drug release during drug dissolution and reduced the dissolution [14]. It is reported that the swelling of polymers influences improvement of dissolution rate of poorly aqueous soluble drugs [15]. Therefore, it is useful to modify the gum in such a way that its swelling ability remains the same and decreases the viscosity.

3.2.1. Viscosity and Swelling Index Measurement. The results of swelling index and viscosity of polymers are given in Table 2. The result indicates that the viscosity of MGG is lower than that of the GG, and swelling index of MGG was not reduced significantly than the GG. Because of swelling nature of the carrier, the extensive surface was increased during the dissolution and thus dissolution rate of drug was enhanced [16].

\subsection{Characterization of Inclusion Complex and Cogrind Mixture}

3.3.1. Differential Scanning Calorimetry (DSC) Study. As shown in Figure 1, the thermograms of the RLX, HP $\beta C D$, and MGG showed respective endothermic peaks at $266.44^{\circ} \mathrm{C}$, $97.46^{\circ} \mathrm{C}$ and $64.95^{\circ} \mathrm{C}$ corresponding to their melting points. In the thermogram of RLX-HP $\beta C D$ complex, the peak of drug disappeared indicating the complexation of RLX with cyclodextrin, whereas in DSC spectra of RLX-MGG Cogrind mixture, the peak of drug was observed, but the intensity was reduced suggesting the conversion of raloxifene hydrochloride from crystalline form to amorphous form.

3.3.2. X-Ray Diffraction Study. As shown in Figure 2, the $\mathrm{X}$-ray diffraction patterns were recorded for pure RLX, HP $\beta C D, M G G$, RLX-HP $\beta C D$ inclusion complex, and RLXMGG Cogrind mixture. PXRD studies were performed in conjunction with DSC to verify the reduction of crystallinity of RLX. Diffraction spectrum of drug sample showed distinct peaks at $2 \theta$ of $12.812^{\circ}, 14.47^{\circ}, 15.784^{\circ}, 19.153^{\circ}, 22.682^{\circ}$, and $25.876^{\circ}$. All these peaks, though of relatively lesser intensity, were observed to be in RLX-HP $\beta C D$ complex and RLXMGG Cogrind mixture. It was thus concluded that the drug was converted from crystalline to amorphous state.

3.3.3. Fourier Transform Infrared Spectroscopy (FT-IR). As shown in Figure 3, FT-IR spectra of RLX exhibited characteristic peaks at 1,642.44 ( $\mathrm{C}=\mathrm{O}$ stretching $), 1,596.15$ (-C-O-Cstretching), 1,466.91 (-S-benzothiofuran), and $905.61 \mathrm{~cm}^{-1}$ (benzene ring). They were well preserved in the RLX-HP $\beta C D$ complex and RLX-MGG Cogrind mixture. These results indicate that no interaction occurred between drug and excipients.

3.3.4. Scanning Electron Microscopy (SEM). As shown in Figure 4, the scanning electron microscopy photomicrographs of RLX shown in Figure 4 show the longer crystals with very specific morphology, whereas for RLX-HP $\beta C D$ complex and RLX-MGG Cogrind mixture, a decrease in crystallinity due to formation of drug-cyclodextrin complex 


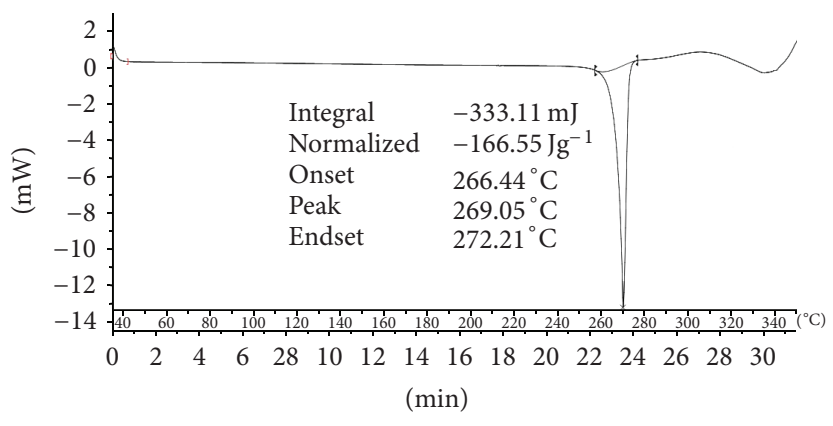

(a)

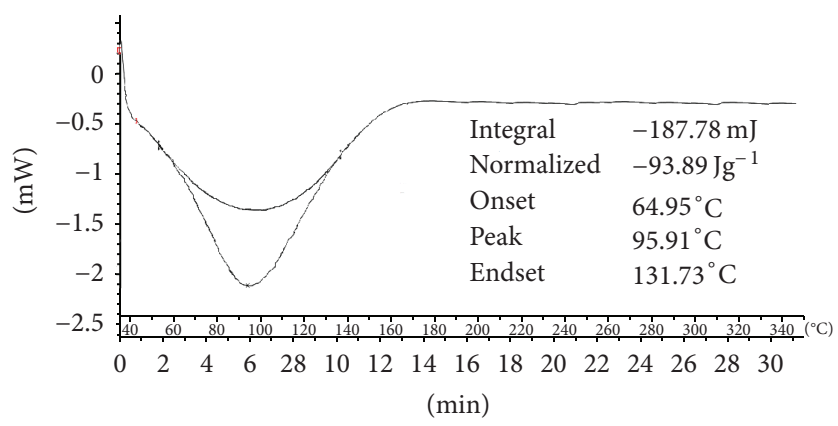

(c)

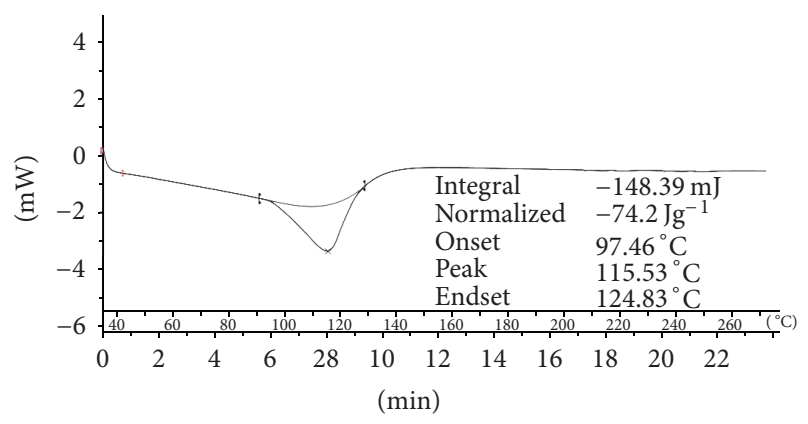

(b)

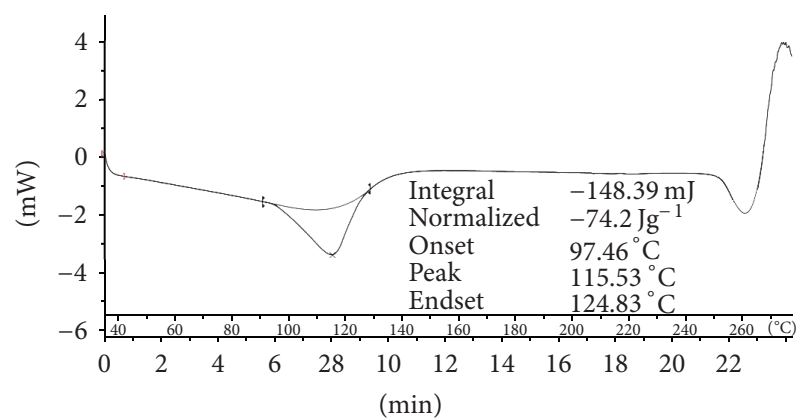

(d)

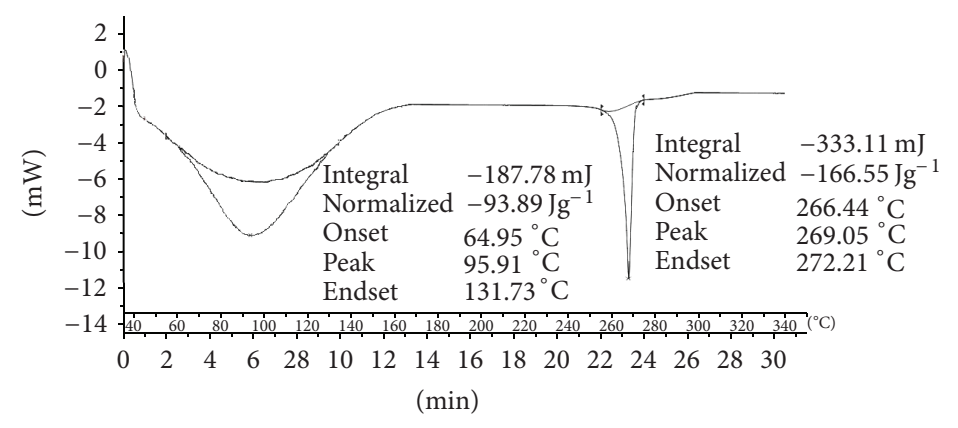

(e)

FIGURE 1: DSC thermogram of (a) raloxifene $\mathrm{HCl}$, (b) $\mathrm{HP} \beta \mathrm{CD}$, (c) modified guar gum, (d) raloxifene-HP $\beta \mathrm{CD}$ inclusion complex and (e) raloxifene-MGG Cogrind mixture.

and molecular dispersion of RLX in the polymer matrix (MGG) was observed, respectively.

\subsubsection{Solubility Study}

Phase Solubility Study of Inclusion Complex. The phase solubility diagram for the complex formation between RLX and $\mathrm{HP} \beta \mathrm{CD}$ is shown in Figure 5. The aqueous solubility of RLX increased linearly with a slope $0.3083\left(r^{2}=0.9926\right)$ as a function of $\mathrm{HP} \beta \mathrm{CD}$ concentration. The apparent solubility constant $K_{c}$, obtained from the slope of the linear phase solubility diagram was found to be $4.5949 \mathrm{~mol}^{-1}$.

Solubility Study of Cogrind Mixture. Solubility data for RLX, RLX-GG and RLX-MGG in different solvents are given in Table 4. ANOVA $(P<0.05)$ performed on solubility parameter demonstrated significant difference between solubility of RLX, RLX-GG and RLX-MGG Cogrinding mixtures. Cogrinding mixture of RLX-MGG showed slight better results than RLX-GG; therefore RLX-MGG was selected for further studies. But there was significant difference between solubility of RLX-HP $\beta$ CD inclusion complex and Cogrinding mixtures.

3.4. In Vitro Dissolution Rate Study. Figure 6 represents in vitro dissolution profiles of RLX, RLX-HP $\beta$ CD inclusion complex, and RLX-MGG Cogrind mixture. Table 5 summarizes \% drug release from the RLX-HP $\beta C D$ inclusion complex and RLX-MGG Cogrind mixture at 60 and $120 \mathrm{~min}$. From Table 5, we can conclude that maximum enhancement in dissolution rate up to $84.47 \% \pm 0.84 \%$ is shown by 


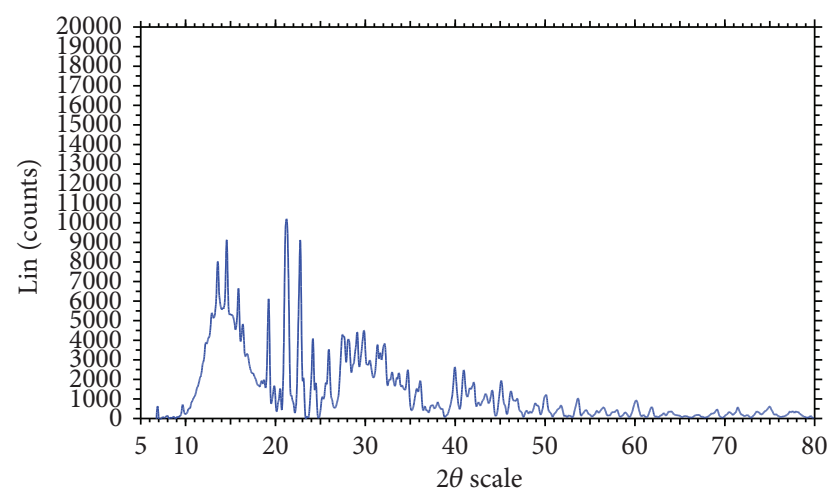

(a)

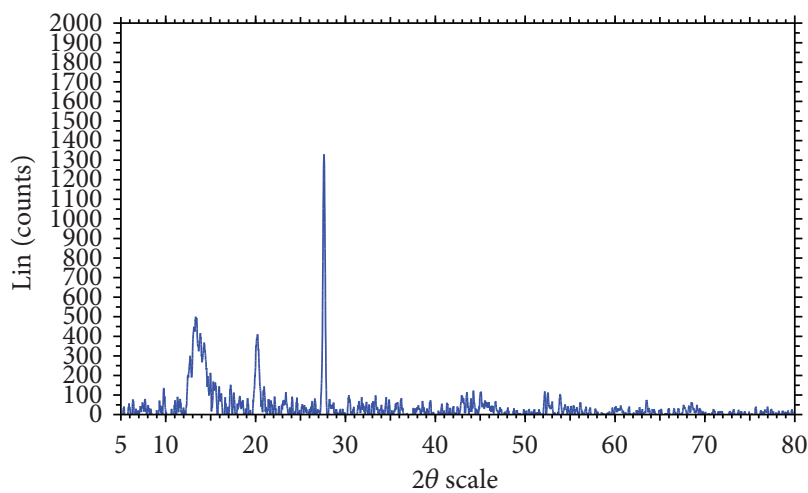

(c)

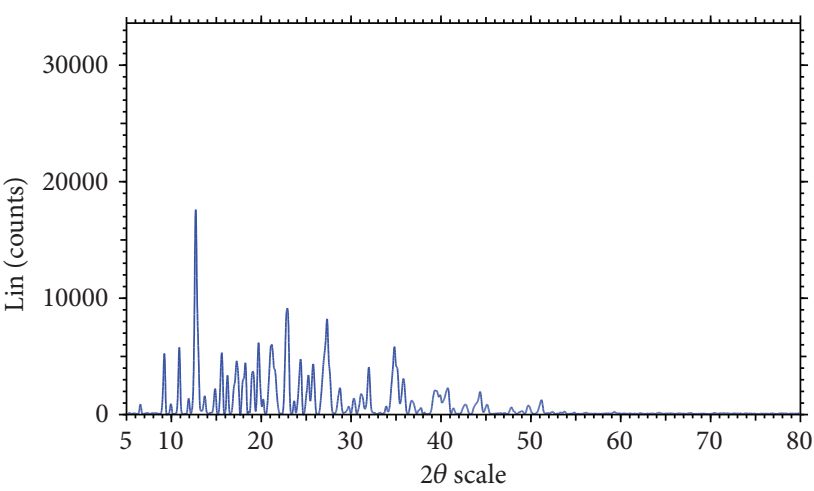

(b)

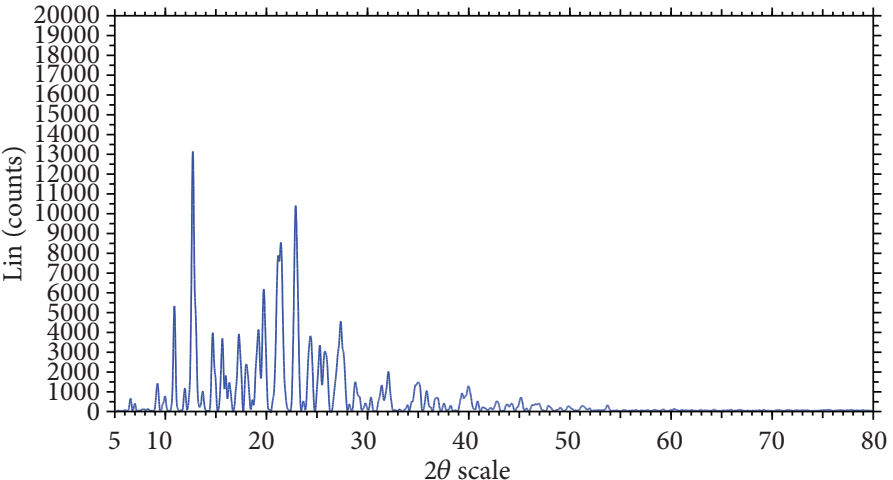

(d)

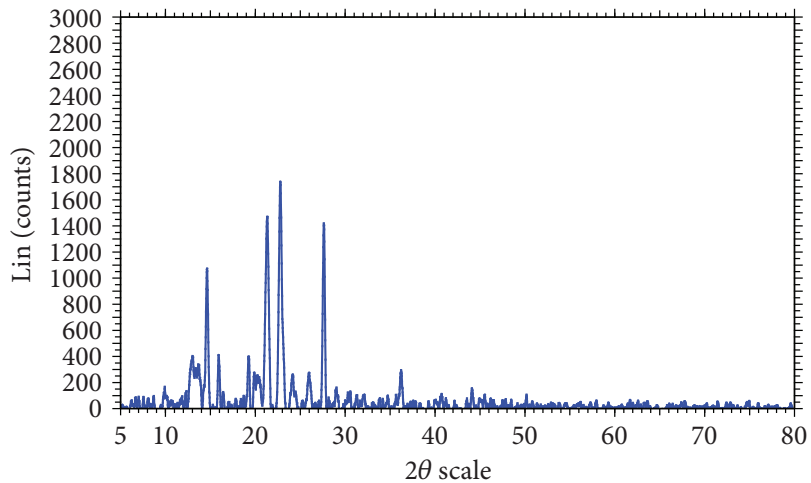

(e)

FIGURE 2: PXRD of (a) raloxifene $\mathrm{HCl}$, (b) $\mathrm{HP} \beta \mathrm{CD}$, (c) modified guar gum, (d) raloxifene-HP $\beta \mathrm{CD}$ inclusion complex and (e) raloxifene-MGG Cogrind mixture.

RLX-HP $\beta$ CD inclusion complex as compared to that of $51.30 \pm 0.57 \%$ by RLX-MGG Cogrind mixture at $120 \mathrm{~min}$. The results of the statistical analysis (ANOVA) suggest significant enhancement of dissolution rate of RLX from RLX-HP $\beta C D$ inclusion complex at all the time points $(P<0.05)$ when compared with plain RLX and RLX-MGG Cogrind mixture.

\section{Conclusion}

The molecular structure of cyclodextrin creates a bucketlike cavity that can function to complex with drug or functional groups on drug. The investigation suggests from phase solubility study and dissolution rate profile of the inclusion complex that the solubility and dissolution rate of raloxifene increases significantly due to $\mathrm{HP} \beta \mathrm{CD}$. Whereas, the Cogrinding method enhances the solubility of RLX by converting it to amorphous form, reducing the particle size and increasing wettability. The optimum ratio for Cogrinding mixture was found to be $1: 8$ which shows higher solubility. Moreover, this natural polymer like guar gum has advantage over other synthetic polymers as these polymers are biocompatible, biodegradable, and having low cost.

Hence, from practical point of view, Cogrinding method appeared easier and was considered as the most convenient method. But when both these techniques were compared the 


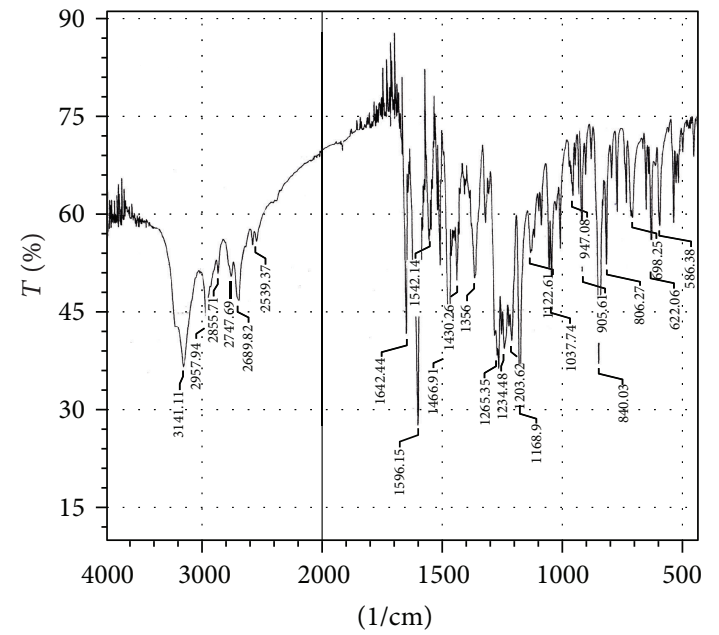

(a)

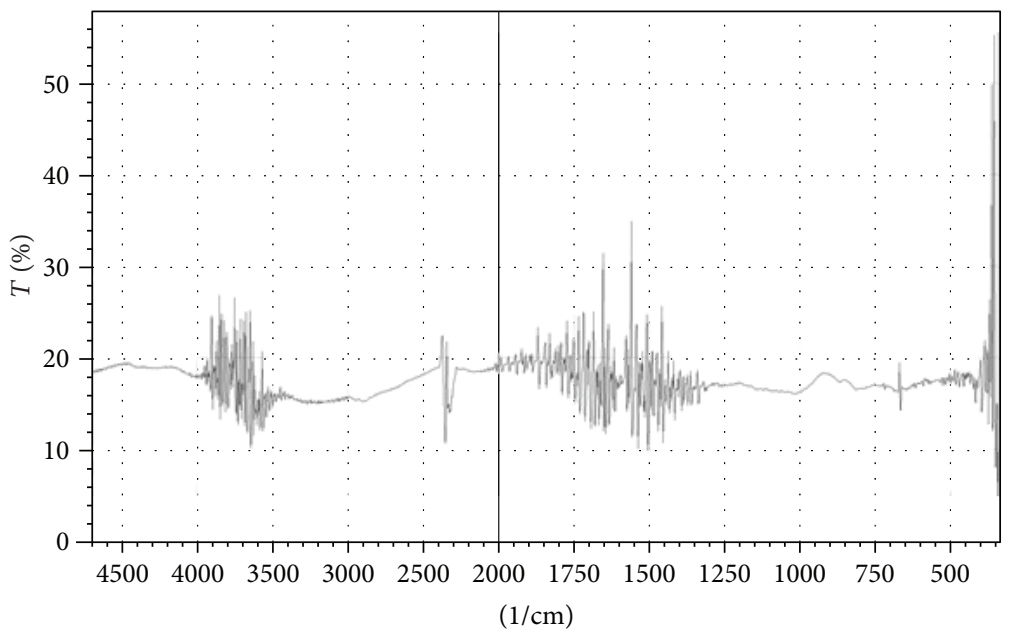

(c)

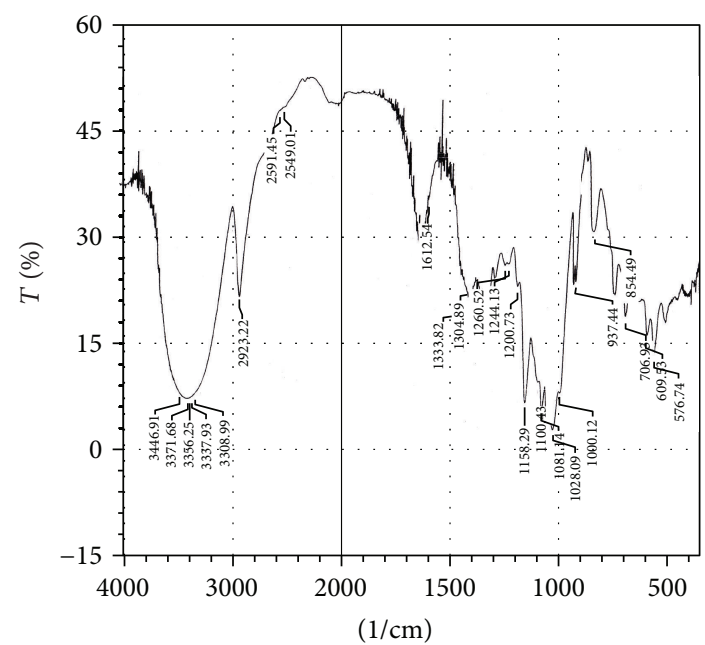

(b)

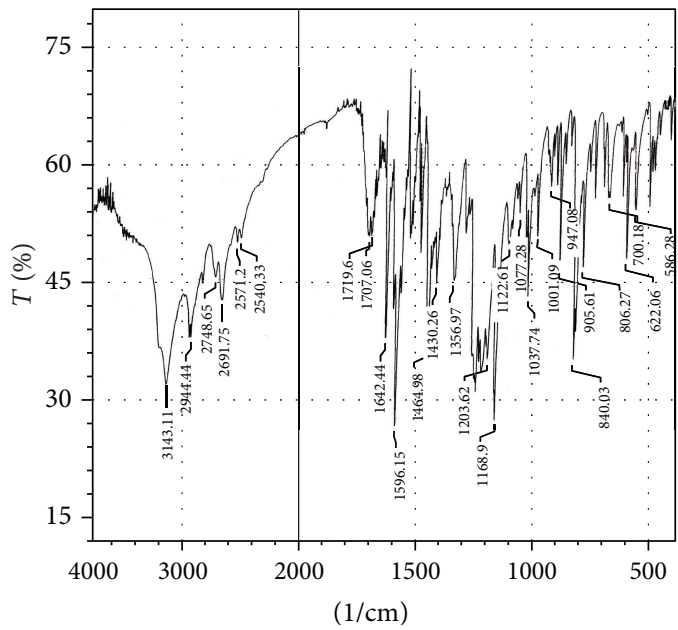

(d)

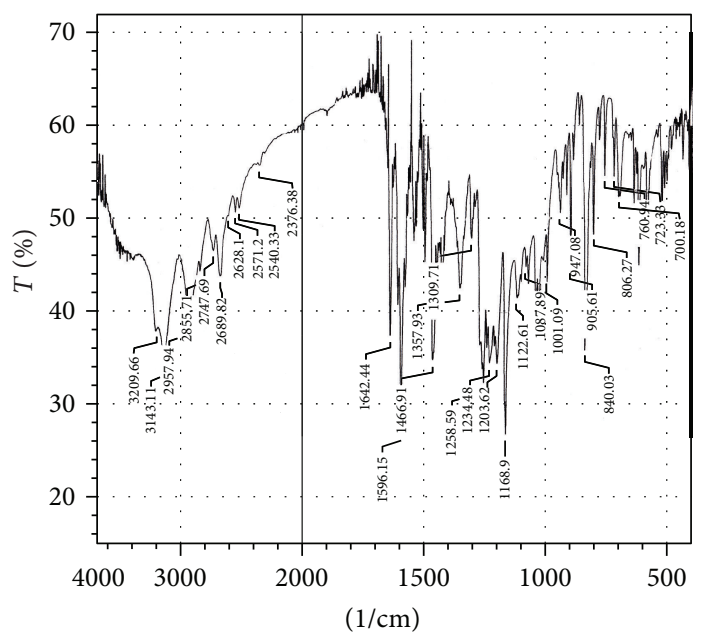

(e)

FIGURE 3: FTIR spectra of (a) raloxifene $\mathrm{HCl}$, (b) $\mathrm{HP} \beta \mathrm{CD}$, (c) modified guar gum, (d) raloxifene- $\mathrm{HP} \beta \mathrm{CD}$ inclusion complex and (e) raloxifene-MGG Cogrind mixture. 


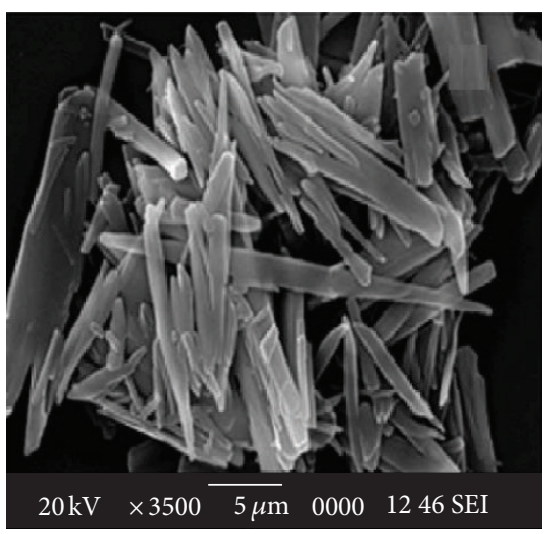

(a)

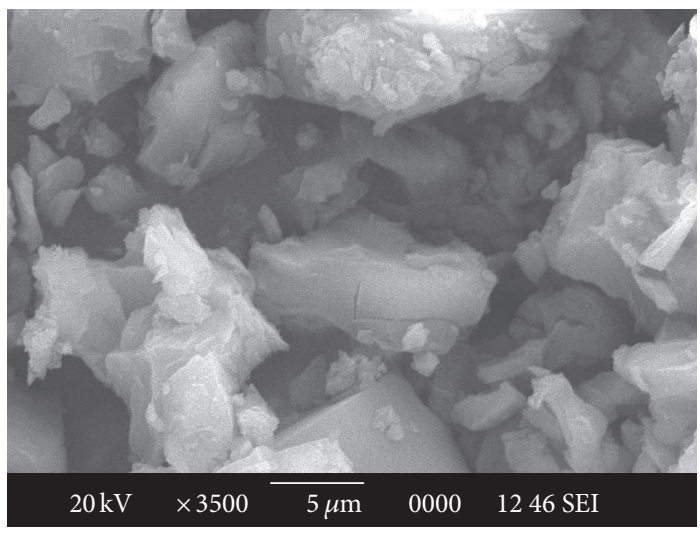

(b)

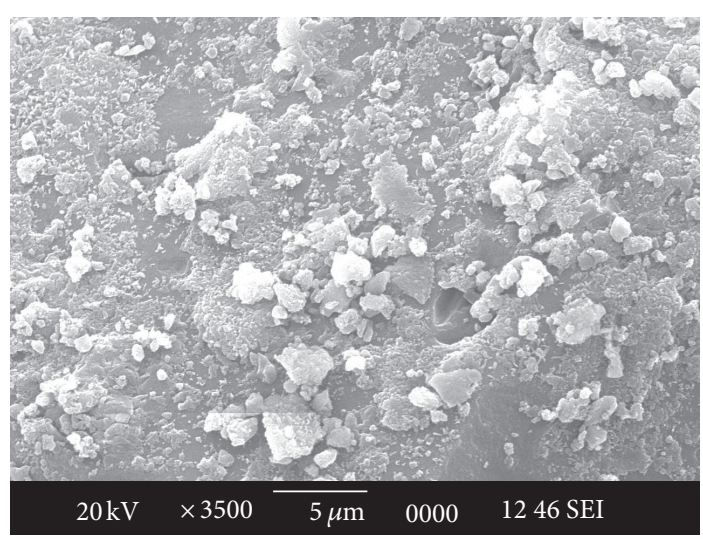

(c)

FIGURE 4: SEM of (a) raloxifene, (b) raloxifene-HP $\beta$ CD inclusion complex and(c) raloxifene-MGG Cogrind mixture.

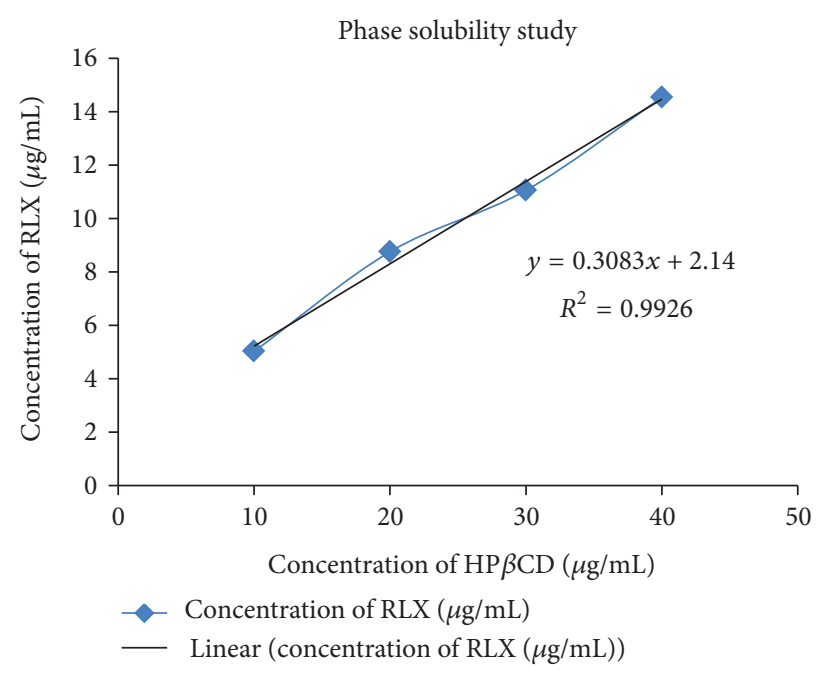

FIGURE 5: Phase solubility diagram of raloxifene.

inclusion complex method showed better results as compared to those of the other methods and thus was found to be more effective than Cogrinding method.

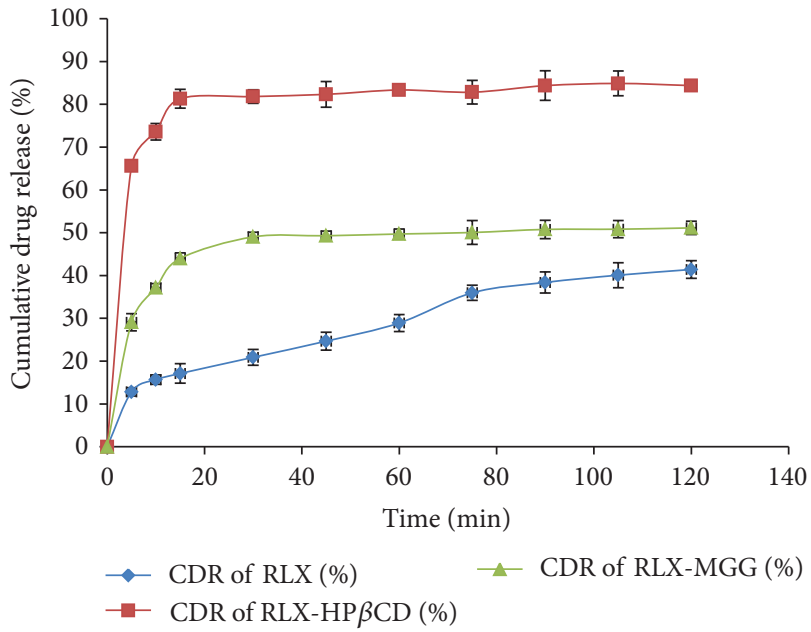

FIGURE 6: Dissolution profile of RLX, RLX-HP $\beta$ CD inclusion complex, and RLX-MGG Cogrind mixture.

\section{Conflict of Interests}

The authors report no conflict of interests. 


\section{Acknowledgment}

The authors are thankful to R. C. Patel Institute of Pharmaceutical Education and Research, Shirpur, for providing all the necessary facilities to carry out this research work.

\section{References}

[1] G. V. Murali Mohan Babu, C. D. S. Prasad, and K. V. Ramana Murthy, "Evaluation of modified gum karaya as carrier for the dissolution enhancement of poorly water-soluble drug nimodipine," International Journal of Pharmaceutics, vol. 234, no. 1-2, pp. 1-17, 2002.

[2] P. Pandya, S. Gattani, P. Jain, L. Khirwal, and S. Surana, "Cosolvent evaporation method for enhancement of solubility and dissolution rate of poorly aqueous soluble drug simvastatin: in vitro-in vivo evaluation," AAPS PharmSciTech, vol. 9, no. 4, pp. 1247-1252, 2008.

[3] V. K. Rai, B. Rajput, M. Sharma, A. Agarwal, A. Gupta, and N. Singh, "Solubility enhancement of poorly water-soluble drug (raloxifene hydrochloride) by using different Hydrophilic binders in solid dosage form," Pharmacie Globale International Journal of Comprehensive Pharmacy, vol. 1, no. 2, pp. 1-5, 2010.

[4] A. Trapani, A. Lopedota, N. Denora et al., "A rapid screening tool for estimating the potential of 2-hydroxypropyl- $\beta$ cyclodextrin complexation for solubilization purposes," International Journal of Pharmaceutics, vol. 295, no. 1-2, pp. 163-175, 2005.

[5] T. R. Bhardwaj, M. Kanwar, R. Lal, and A. Gupta, "Natural gums and modified natural gums as sustained-release carriers," Drug Development and Industrial Pharmacy, vol. 26, no. 10, pp. 1025-1038, 2000.

[6] R. C. Rowe, P. J. Sheskey, and P. J. Weller, Handbook of Pharmaceutical Excipients, Pharmaceutical Press, London, UK, 5th edition, 2003.

[7] A. Portero, C. Remunan-Lopez, and J. L. Vila-Jata, "Effect of chitosan and glutamate enhancing the dissolution properties of the poorly water soluble drug nifedipine," International Journal of Pharmaceutics, vol. 175, pp. 75-84, 1998.

[8] B. Yang, J. Lin, Y. Chen, and Y. Liu, "Artemether/hydroxypropyl- $\beta$-cyclodextrin host-guest system: characterization, phase-solubility and inclusion mode," Bioorganic and Medicinal Chemistry, vol. 17, no. 17, pp. 6311-6317, 2009.

[9] M. Patel, A. Tekade, S. Gattani, and S. Surana, "Solubility enhancement of lovastatin by modified locust bean gum using solid dispersion techniques," AAPS PharmSciTech, vol. 9, no. 4, pp. 1262-1269, 2008.

[10] D. Derle, S. H. S. Boddu, and M. Magar, "Studies on the preparation, characterization and solubility of $\beta$-cyclodextrinsatranidazole inclusion complexes," Indian Journal of Pharmaceutical Education and Research, vol. 40, pp. 232-236, 2006.

[11] S. Gauthami and V. R. Bhat, A Monograph on Gum Karaya, National Institute of Nutrition, Indian Council of Medical Research, Hyderabad, India, 1992.

[12] H. S. Mahajan, S. K. Shah, and S. J. Surana, "Nasal in situ gel containing hydroxy propyl $\beta$-cyclodextrin inclusion complex of artemether: development and in vitro evaluation," Journal of Inclusion Phenomena and Macrocyclic Chemistry, vol. 70, no. 12, pp. 49-58, 2011.

[13] T. Higuchi and K. A. Connors, "Phase solubility technique," Advance Analytical Chemistry Instrument, vol. 4, pp. 117-212, 1965.
[14] G. H. P. Te Wierik, G. K. Bolhuis, K. Zuurman, and C. F. Lerk, "Improvement of dissolution of poorly soluble drugs by solid deposition on a super disintegrant. I. Physical mixtures," Acta Pharmaceutica Nordica, vol. 4, no. 4, pp. 239-244, 1992.

[15] G. K. Bolhuis, K. Zuurman, and G. H. P. Te Wierik, "Improvement of dissolution of poorly soluble drugs by solid deposition on a super disintegrant. II. The choice of super disintegrants and effect of granulation," European Journal of Pharmaceutical Sciences, vol. 5, no. 2, pp. 63-69, 1997.

[16] M. Westerberg, B. Jonsson, and C. Nystrom, "Physicochemical aspects of drug release. IV. The effect of carrier particle properties on the dissolution rate from ordered mixtures," International Journal of Pharmaceutics, vol. 28, no. 1, pp. 23-31, 1986. 

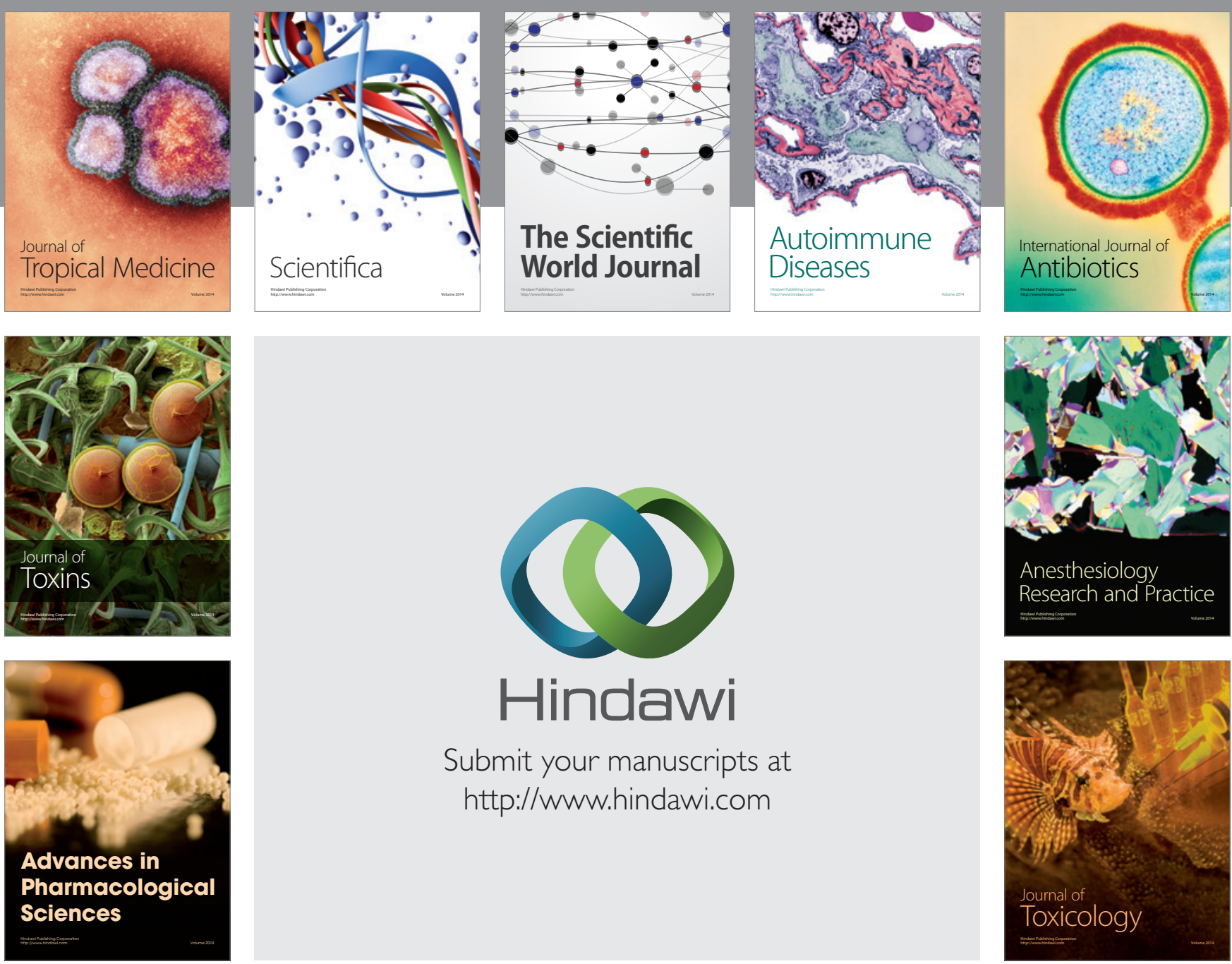

\section{Hindawi}

Submit your manuscripts at

http://www.hindawi.com
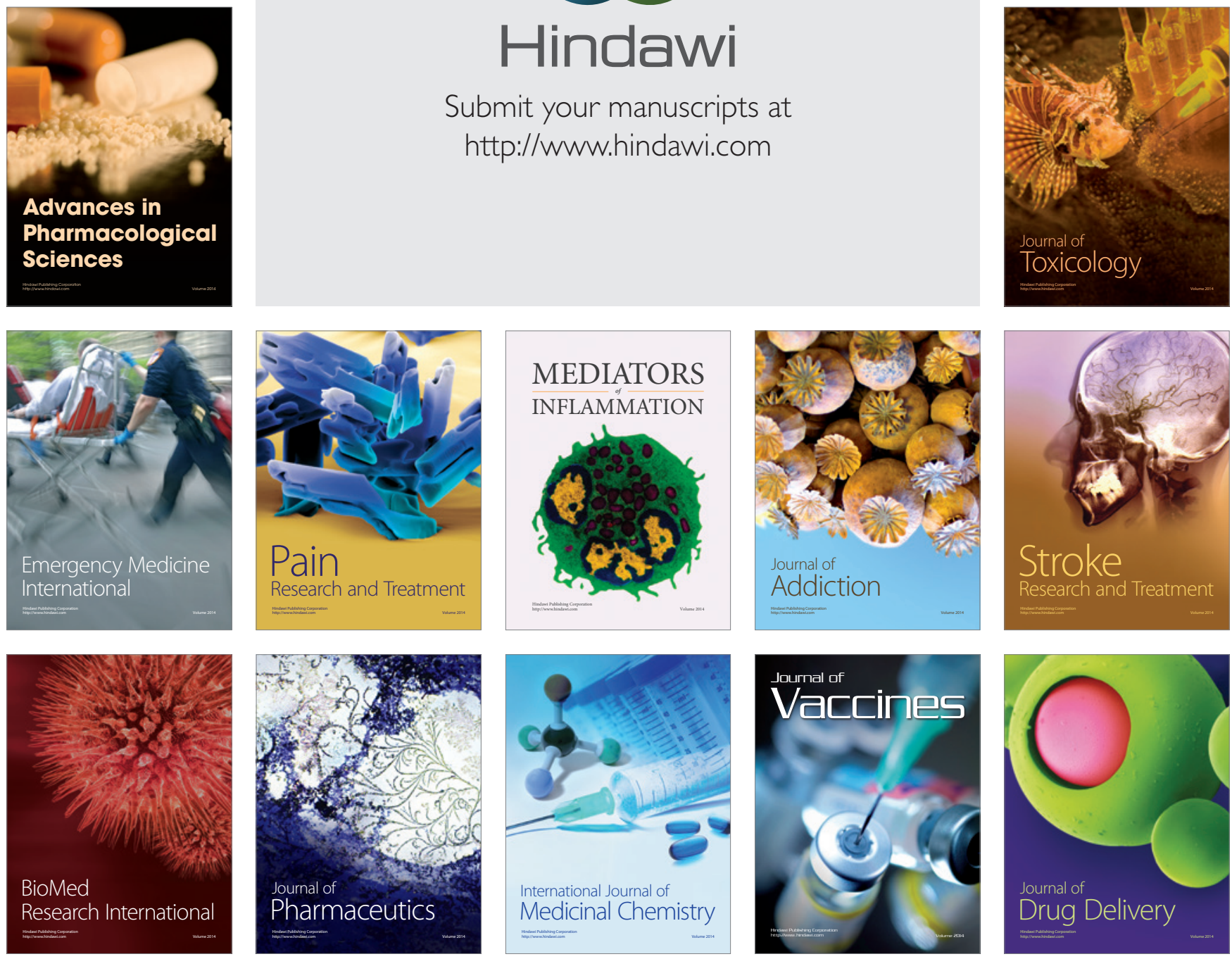